\title{
Using eHealth to engage and retain priority populations in the HIV treatment and care cascade in the Asia-Pacific region: a systematic review of literature
}

Julianita Purnomo ${ }^{1 * \dagger}$ (B), Katherine Coote ${ }^{1 \dagger}$, Limin Mao ${ }^{2}$, Ling Fan ${ }^{1}$, Julian Gold ${ }^{1,3}$, Raghib Ahmad ${ }^{1}$ and Lei Zhang ${ }^{4,5,6,7^{*}}$

\begin{abstract}
Background: The exponential growth in the reach and development of new technologies over the past decade means that mobile technologies and social media play an increasingly important role in service delivery models to maximise HIV testing and access to treatment and care. This systematic review examines the impact of electronic and mobile technologies in medical care (eHealth) in the linkage to and retention of priority populations in the HIV treatment and care cascade, focussing on the Asia-Pacific region.

Methods: The review was informed by the Preferred Reporting Items for Systematic Reviews and Meta-Analyses (PRISMA) statement from the Cochrane Collaboration guidelines. Both grey and published scientific literature from five different databases were searched for all original articles in English published from 2010 to 2017. Studies conducted outside the Asia-Pacific region or not including HIV priority populations were excluded. The methodological quality of studies included in the review was assessed using the Quality Assessment Tool for Quantitative Studies.

Results: The database search identified 7309 records. Of the 224 peer-reviewed articles identified for full text review, 16 studies from seven countries met inclusion criteria. Six cross sectional studies found evidence to support the use of eHealth, via text messages, instant messaging, social media and health promotion websites, to increase rates of HIV testing and re-testing among men who have sex with men (MSM). Evidence regarding the efficacy of eHealth interventions to improve antiretroviral treatment (ART) adherence was mixed, where one randomised controlled trial (RCT) showed significant benefit of weekly phone call reminders on improving ART adherence. Three further RCTs found that biofeedback eHealth interventions that provided estimated ART plasma concentration levels, showed promising results for ART adherence.

Conclusions: This review found encouraging evidence about how eHealth can be used across the HIV treatment and care cascade in the Asia-Pacific region, including increasing HIV testing and re-testing in priority populations as well as ART adherence. eHealth interventions have an important role to play in the movement towards the end of AIDS, particularly to target harder-to-reach HIV priority populations, such as MSM.
\end{abstract}

Keywords: HIV, Treatment cascade, Testing, Key population, Asia-Pacific, mHealth, Mobile phone, Social media, Review

\footnotetext{
*Correspondence: lia.purnomo@health.nsw.gov.au;

lei.zhang1@monash.edu.au

${ }^{\dagger}$ Equal contributors

'The Albion Centre, South Eastern Sydney Local Health District, 150-154

Albion Street, Sydney, NSW 2010, Australia

${ }^{4}$ Research Center for Public Health, Tsinghua University, Beijing 100084,

China

Full list of author information is available at the end of the article
} 


\section{Background}

The term HIV treatment and care cascade describes the process of HIV testing, linkage to and retention in care, initiation and adherence to antiretroviral treatment (ART), and ultimately, viral load suppression. Achieving the ultimate outcome of the cascade results directly in improved health outcomes for people living with HIV (PLHIV) and reduced risk of HIV transmission [1]. To maximise the benefits of ART, individuals must progress along the continuum of care promptly after HIV infection. HIV testing is a critical first step in linking PLHIV to the HIV treatment and care cascade, where it also provides an important opportunity to reinforce prevention against HIV transmission. Although HIV testing and treatment programme coverage is improving globally since 2011 in the era of Treatment as Prevention, disengagement from HIV clinical care at each stage of the treatment and care cascade still occurs. Linkage to and retention in HIV clinical care are critical to achieving universal access to HIV treatment and care with the aim of sustained HIV viral suppression [2, 3].

The roles of electronic health (eHealth) and mobile health (mHealth) in health care are expanding. The World Health Organization (WHO) Global Observatory for eHealth (GOe) defines eHealth as "the use of information and communication technologies (ICT) for health". This encompasses the delivery of health information for health professionals and health consumers, through the internet and telecommunications [4]. The GOe defines mHealth as "medical and public health practice supported by mobile devices, such as mobile phones, patient monitoring devices, personal digital assistants (PDAs), and other wireless devices" [5]. This paper will use the general term eHealth to denote eHealth, mHealth, and ICT, and will refer to specific technologies where applicable.

Accessibility to the internet and mobile phones internationally and particularly in developing economies in the Asia-Pacific is surging [6]. Six in ten people from AsiaPacific countries subscribed to mobile services, with 1.7 billion smartphone connections at the end of 2015. By $2020,74 \%$ of the region's population is expected to have a mobile subscription and will add a further 1.3 billion smartphone connections, reaching two-thirds of the region's total connections [7]. The impact of eHealth on the outcomes of health promotion and health care access and delivery are increasingly examined across a wide range of diseases and health behaviours [5, 8-11]. The benefits of text messaging for improving clinical outcomes and attendance in chronic disease self-management have been well documented $[8,11]$.

For PLHIV, eHealth is increasingly being integrated into HIV-related disease self-management and service delivery. While short message service (SMS) interventions are evidenced to be effective in enhancing ART adherence [11-14], eHealth overall is considered as the most promising approach to deliver cost-effective interventions along the HIV treatment and care cascade [15-19].

HIV priority populations, groups at increased risk of HIV due to specific higher-risk behaviours [20], are typically harder-to-reach due to stigma and discrimination in relation to HIV and associated behavioural patterns. Research from Asia-Pacific countries has shown that eHealth interventions are considered acceptable and feasible modalities to engage populations ranging from men who have sex with men (MSM), transgender women to female sex workers [21-34].

Based on the aforementioned advantages, global health and development agencies (e.g. WHO and the United Nations Population Fund [UNFPA]) have identified the potential for eHealth in improving HIV outcomes [20,35]. Existing reviews of eHealth interventions targeting PLHIV focus on the application of specific devices (such as mobile phones [36, 37], telephone [38, 39], and computer [40]) and particular technology functions (such as text messaging [12, 41], internet [42], mobile phone applications (apps) [43], social media [44] and social marketing [45]), across a range of HIV priority populations. However, limited reviews have investigated the use of eHealth in the context of the HIV treatment and care cascade to improve service engagement among HIV priority populations. The most commonly researched HIV priority populations were MSM, with a focus on HIV prevention and testing [42, 45, 46]. Catalani et al. systematically reviewed the published literature and reported a lack of evidence concerning the use of eHealth to address the needs of a range of priority populations, including MSM up to 2011 [47].

The Asia-Pacific covers the World Health Organization (WHO) divisions of the Western Pacific Region and South East Asia Region. These geographically linked regions encompass diversity in cultures and economies, as well significant uptake of mobile technology innovations, particularly in South East Asia [5]. This review focusses on the Asia-Pacific region to inform future HIV policy and programming in these parts of the world.

To our knowledge, no review has yet examined the use eHealth targeting all HIV priority populations across the entire HIV care continuum in the Asia-Pacific region. This systematic review aims to describe and critically examine, the uptake of eHealth interventions applied to engage and retain priority populations in HIV treatment and care, in the Asia-Pacific region.

\section{Methods}

This review followed the PRISMA (Preferred Reporting Items for Systematic Reviews and Meta- Analyses) guidelines [48] and used a guided approach to retrieve relevant 
studies. The review included all experimental (randomised controlled trials or case-control studies) and observational (cross-sectional or longitudinal) studies that examine the impacts of different types of eHealth interventions in engaging and retaining priority populations in the HIV testing, treatment and care cascade within the Asia-Pacific region. Qualitative studies were excluded from this review.

\section{Search strategies and selection criteria}

The Population, Intervention, Comparison, Outcome (PICO) model was used to develop inclusion criteria and search terms. In consultation with a librarian (LF), a search strategy was developed to locate all relevant studies. Priority populations were the selected population, referring to MSM, sex workers (SW), people who inject drugs (PWID) and transgender (TG) people. Interventions included: internet (internet-based, web-based and online intervention), social media (e.g. education initiatives, direct messaging, social marketing, partner referrals, linkage to testing sites, delivery of postal tests, etc.), cell phone, text messaging, mobile apps, reminder systems, computer (e.g. personal computer, laptop, handheld and ultra-portable computer, etc.), personal digital assistant (PDA), portable media player, handheld video-games console (e.g. Playstation Portable), telemedicine/telehealth conducted in Asia-Pacific countries. All types of comparison and no comparison were incorporated in this review. Outcomes comprised of behavioural outcomes (HIV testing uptake, HIV re-testing rates); biomedical outcomes (viral load, CD4+ T-cell counts, HIV-related mortality and morbidity rates); and treatment adherence measurement (pill counts, electronic monitoring, patient self-report, medication diaries, clinic or pharmacy reports).

Combining terms related to HIV, eHealth, HIV treatment and care cascade and priority populations (Table 1), electronic searches for peer-review articles were performed in PubMed, MEDLINE, EMBASE, Cumulative Index of Nursing and Allied Health (CINAHL) and Web of Science. Grey literature was obtained from the: Cochrane Library; World Health Organization Library Information System (WHOLIS); World Bank e-Library; British HIV/AIDS Association (BHIVA); International AIDS Society; International AIDS Conference; and Australasian HIV/AIDS conference databases. The search included a wide range of Medical Subject Heading $(\mathrm{MeSH})$ terms, subject headings, free-text terms with all potential synonyms, related terms and variant spellings using truncation and combinations, keywords and controlled vocabulary search terms derived from review questions. Subject terms were identified through preliminary exploration searches of the above electronic databases.

Initially the review was limited to published and unpublished studies including in press and in progress articles between January 2010 and December 2014. A subsequent search was conducted to extend the review period up until June 2017. Studies were excluded if they were not in English, were conducted outside the AsiaPacific region, or did not include priority populations. In this review article, the term "Asia-Pacific" refers to the following countries: Australia, Bangladesh, Brunei, Cambodia, China, Cook Islands, Fiji, Hong Kong, India, Indonesia, Japan, Kiribati, Korea, Lao People's Democratic Republic, Malaysia, Maldives, Mongolia, Myanmar, Nepal, New Zealand, Pakistan, Papua New Guinea, Philippines, Sri Lanka, Taiwan, Thailand, Timor-Leste, Samoa, Singapore, Solomon Islands, Tonga, Vanuatu, and Vietnam.

Duplicate publications and publications derived from the same data sources were excluded using a combined strategy of auto and hand-searching methods. Systematic reviews previously performed on these topics were also excluded. The reference lists of key articles were handsearched to locate additional studies.

Search results from the twelve databases were downloaded into EndNote X7 software. Two EndNote libraries were created, one for testing and linkage into the HIV treatment and care cascade literature and one for

Table 1 List of terms for literature search

\begin{tabular}{|c|c|c|}
\hline \multicolumn{2}{|l|}{ Source } & \multirow{2}{*}{$\begin{array}{l}\text { Variations of the following search terms were used } \\
\text { HIV, AIDS }\end{array}$} \\
\hline \multirow{4}{*}{$\begin{array}{l}\text { PubMed, MEDLINE, EMBASE, CINAHL, Web of } \\
\text { Science, Cochrane Library, WHOLIS, World Bank } \\
\text { e-Library, BHIVA, International AIDS Society, } \\
\text { International AIDS Conference, The Australasian } \\
\text { HIV/AIDS conference }\end{array}$} & HIV infection & \\
\hline & Technology intervention & $\begin{array}{l}\text { mHealth, mobile health, cellular phone, cell phone, mobile phone, } \\
\text { handphone, smartphone, personal digital assistant, portable media } \\
\text { player, handheld video-game consoles, computer, personal computer, } \\
\text { handheld and ultra-portable computer, desktop, laptop, palm pilot, } \\
\text { netbook, mobile application, SMS, MMS, text messaging, reminder } \\
\text { systems, email, instant messaging, chat room, live chat, multimedia, } \\
\text { blogging, podcast, social media, Facebook, Twitter, MySpace, YouTube, } \\
\text { social networking, internet forums, wireless technology, wi-fi, world } \\
\text { wide web, website, internet, online, eHealth, telehealth, telemedicine }\end{array}$ \\
\hline & $\begin{array}{l}\text { HIV treatment and care } \\
\text { cascade }\end{array}$ & $\begin{array}{l}\text { Testing, screen, diagnose, retention, linkage, care, cascade, follow up, } \\
\text { counselling, treatment, suppression, PrEP, PEP, ART, medication } \\
\text { adherence }\end{array}$ \\
\hline & Priority population & MSM, sex workers, people who inject drugs, transgender \\
\hline
\end{tabular}


retention in the HIV treatment and care cascade literature. Examples of each search strategy conducted in PubMed are presented in Appendix 1 (see Additional file 1). Search terms were modified in other electronic databases.

\section{Screening and data extraction}

After the removal of duplicates, titles and abstracts of identified articles were screened for relevance to this systematic review by two reviewers (JP, KC). When it was not clear whether the abstract met the inclusion criteria, the full text of potentially relevant studies was reviewed. Failure to meet any of the eligibility criteria resulted in exclusion from the review. The number of excluded studies and reasons for exclusion were recorded at each selection stage. In the case of any disagreement, the articles were discussed by the two reviewers (JP, KC), and further dispute was resolved in consultation with an additional two reviewers (LZ, LM).

Data were extracted using a standardised abstraction form by one reviewer (JP) and independently verified by a second (KC). The following information was gathered from each included study: country, study design, study population, sample size, technology mode, the purpose of the study, study description, study duration, key outcomes of interest and results or authors' conclusions.

\section{Quality assessment}

The methodological quality of all included studies was assessed using the Quality Assessment Tool for Quantitative Studies $[49,50]$. This tool enables a global rating of 'weak', 'moderate' or 'strong' measured by potential selection bias, study design, confounders, blinding, data collection methodology and reporting of withdrawals and dropouts. Component ratings were scored according to the criteria specified in the dictionary that accompanies the assessment tool [49].

A meta-analysis was not performed due to the heterogeneity of intervention types, study designs, study populations and outcome variables among the included studies. Instead, a descriptive summary of the findings across studies was created, based on key themes and outcomes.

\section{Results}

The initial database search (Fig. 1) identified 4965 articles. On removal of duplicates, 3755 peer review articles remained. Fourteen additional articles from handsearching and grey literature search were included in the title and abstract review phase. After preliminary screening of titles and abstracts by the reviewers, 163 potentially relevant articles were examined in full against the inclusion and exclusion criteria. Of these, twelve studies [17, 51-61] fulfilled the inclusion criteria. A further article [61] was excluded as it became apparent that it reported on duplicate data from the same data source
[59]. The subsequent literature search (to June 2017) found five additional articles [62-66] which met the inclusion criteria, so that the final sample was 16 eligible papers (Tables 2, 3 and 4).

\section{Characteristics of the included studies}

The studies included in the analysis were conducted in seven Asia-Pacific countries and territories: Australia $(n=4)$, China $(n=6)$, India $(n=2)$, New Zealand $(n=1)$, Pakistan $(n=1)$, Taiwan $(n=1)$ and Vietnam $(n=1)$. Target populations included MSM $(n=7)$, PLHIV $(n=8)$, and HIV positive MSM $(n=1)$. Seven of the included studies were crosssectional, seven were randomised controlled trials (RCT) and two were cohort studies. A total of 8869 individuals were involved in the included studies. The sample size of the RCT studies varied from 28 to 613 participants. The type of devices used to deliver eHealth interventions in engaging and retaining priority populations in the HIV treatment and care cascade were mobile phone $[17,56,57,59,64]$, smartphone [58], and wireless monitoring device [60, 65]. The technology functions used were voice functionality of mobile phone [17, 56, 57, 59], mobile phone alarm [57], interactive voice response (IVR) [64], smartphone apps [58], SMS/text messaging [51, 53], pictorial message [59], instant messaging [53], World Wide Web access [54, 55, 62, 63, 66] and web 2.0/social media [52, 62] (details in Tables 2, 3 and 4).

The sixteen included studies were catagorised into two research foci: seven investigating eHealth applications to testing and linkage to care; and nine examining eHealth applications to HIV treatment and adherence. The methodological quality of each study included in the review was assessed and summarised in Table 5. The evaluation of the methodological quality of the HIV testing and linkage to care studies rated two studies as 'moderate' [51, 52], and five studies as 'weak' [53-55, 62, 63]. Quality limitations in particular related to study design, data collection methods and attrition rates.

Five RCT studies on eHealth applications to HIV treatment and adherence rated 'strong' in methodological quality $[17,56,58,59,65]$. Two further RCT studies were rated as 'moderate' due to limitations in study blinding, selection bias and data collection method $[60,66]$. One cross-sectional and one cohort study were rated as 'weak' $[57,64]$. The key limitations of these studies were related to study design, data collection methods, selection bias, and attrition rates.

\section{eHealth applications to increase HIV testing and linkage to care}

A cross-sectional study found that SMS reminders can significantly increase HIV re-testing rates $(64 \%$ vs. $30 \%$, $p<0.001)$ among HIV-negative MSM across a ninemonth period. The study found those who received SMS reminders were 4.4 more likely ( $95 \%$ CI 3.5 to 5.5 ) to 


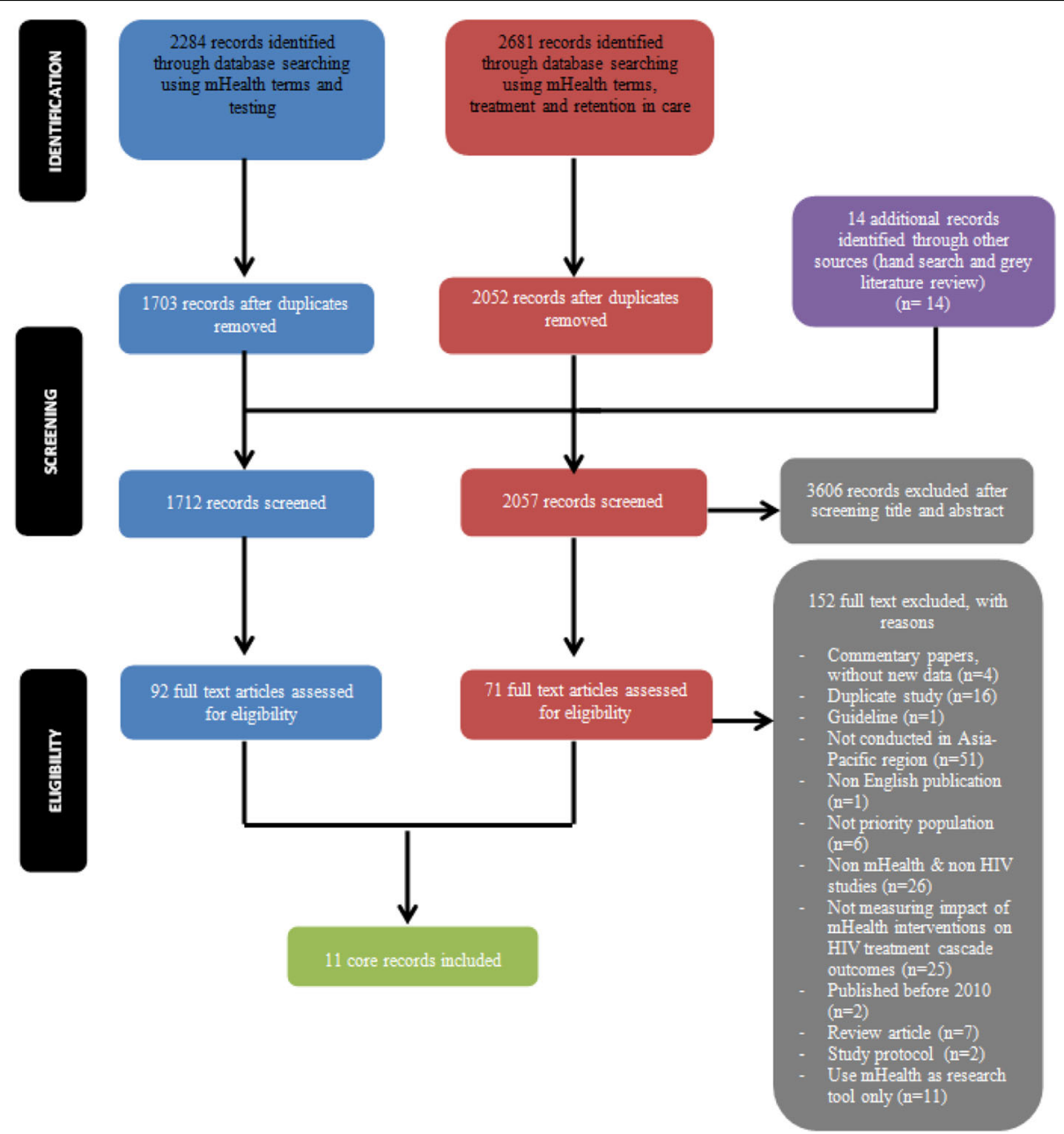

Fig. 1 PRISMA Flow Diagram

re-test than the comparison group [51]. Another crosssectional study reported that instant messaging (IM), ${ }^{1}$ targeting MSM through partner-seeking websites, was effective in prompting one out of every four MSM contacted through IM to present for testing [53]. However, in this study, the financial incentive offered for testing was possibly a confounding factor regarding the efficacy of the IM intervention alone.

Social media campaigns were also effective in reaching MSM and encouraging testing. A cross-sectional study used internet popular opinion leaders (iPOL) to post clips and chat about HIV prevention and testing via a MSM Facebook site. MSM who had visited the site were significantly more likely to have tested for HIV in the past six months $(43.89 \%$ vs. $22.31 \%, \mathrm{x} 2=54.8, \mathrm{df}=1, p<$ 0.001) compared with MSM who had visited a control site [52]. A cross sectional study from China reported increased HIV testing and linkage to care following a six year implementation of internet prevention tools to link MSM to offline HIV testing and care services [62].
The review retrieved two cross-sectional studies that found HIV promotional websites can increase HIV testing. Minas et al. [54] evaluated the impact of a promotional website as part of a multi-modal communication strategy about non-occupational post-exposure prophylaxis (nPEP) for HIV prevention. The web-based health promotion led to an improvement in the proportion of clients tested for HIV at three to four months after initial visit for nPEP (38.8\% in $2002-2005$ to $51.9 \%$ in 2008-2010, $p=0.023$ ). While there was evidence of improvement in appropriate post nPEP testing during the campaign period, the study design precluded establishing any individual impact of the website on HIV testing and prevention, as distinct from any other element of the communication strategy. Pedrana et al. [55] assessed the impact of a social marketing campaign that employed multiple advertising channels to promote a website which provided MSM-targeted information about HIV and sexual health, including testing. Compared with the pre-campaign period, Poisson regression 


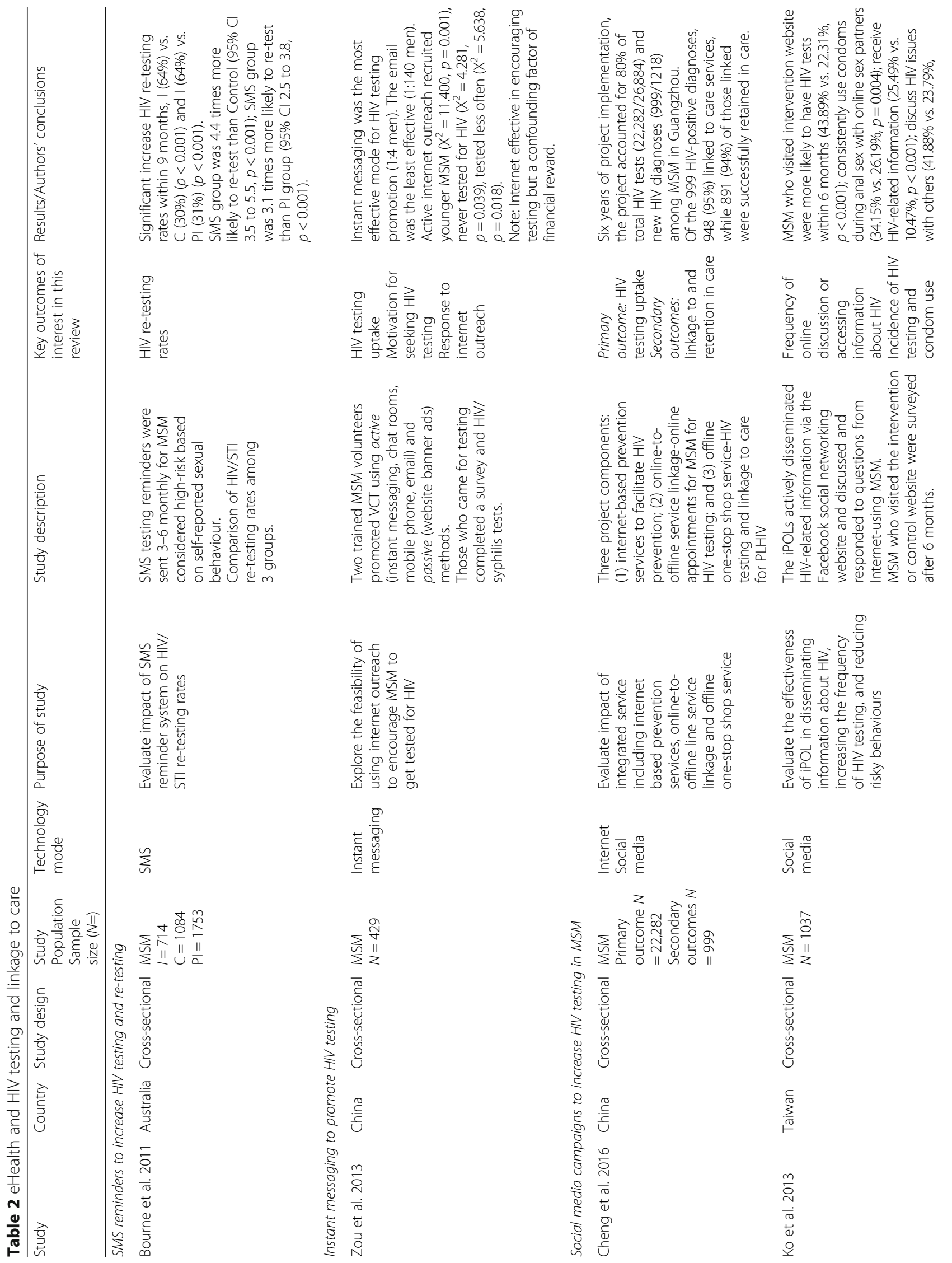




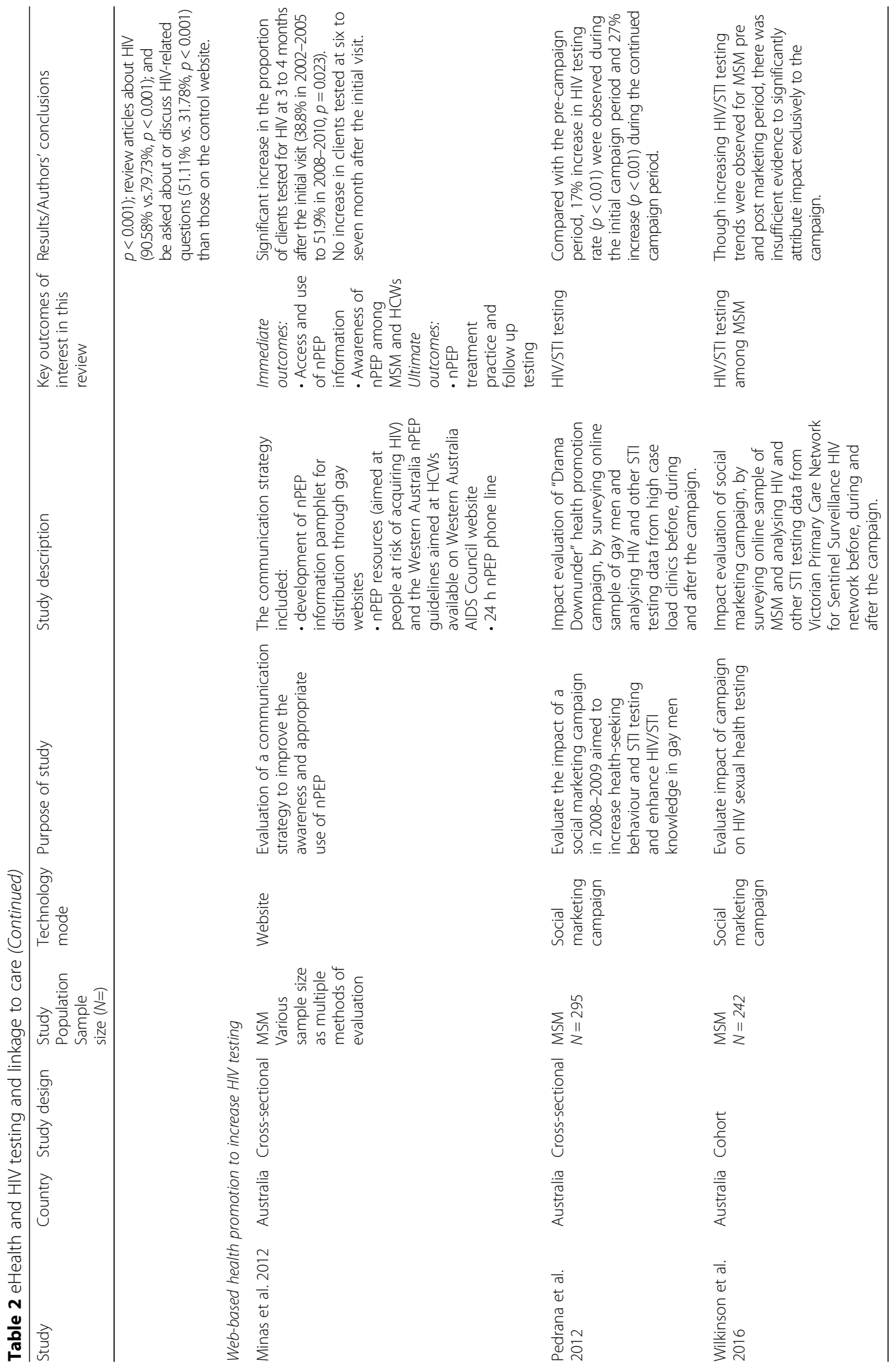




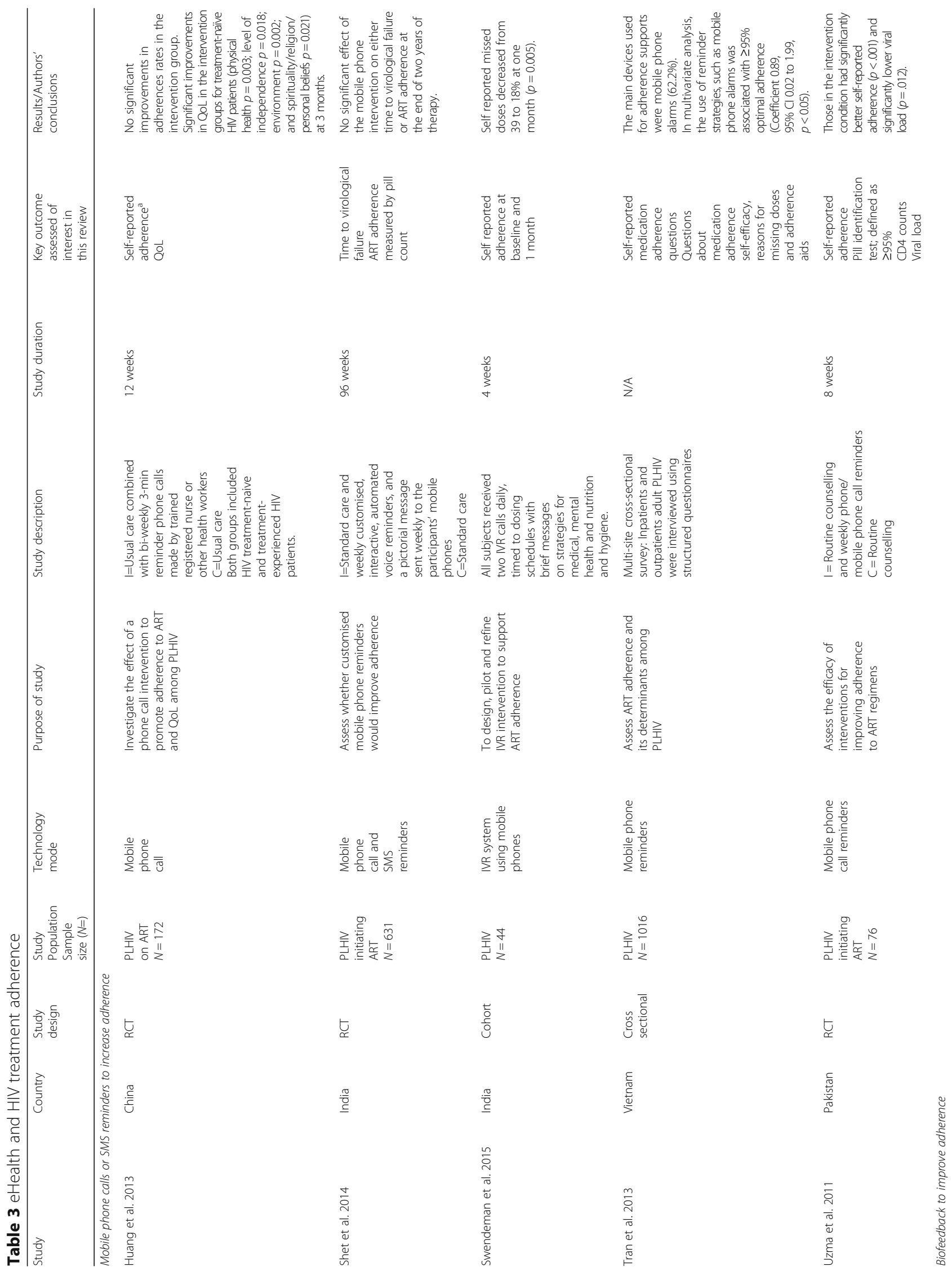




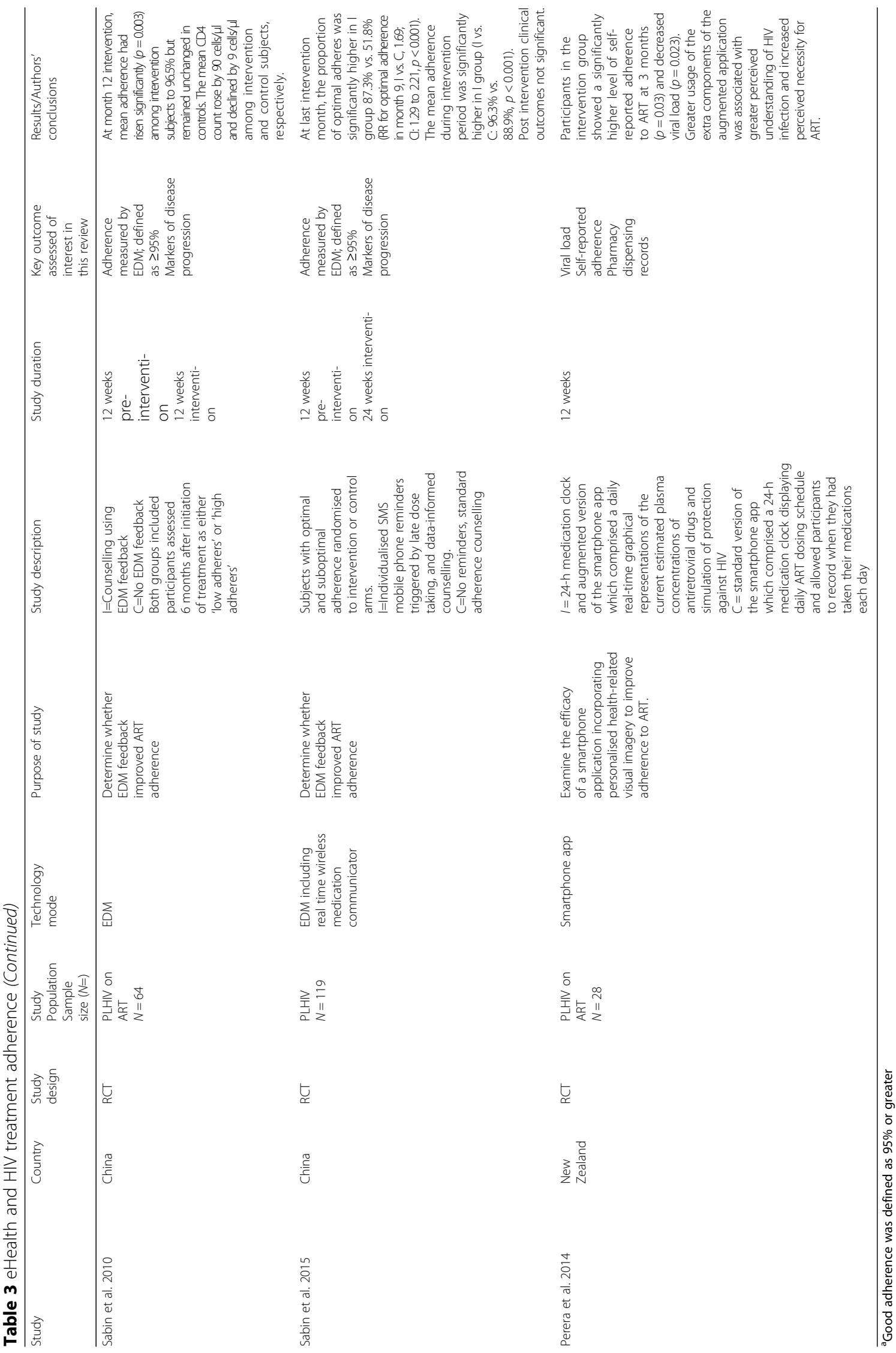




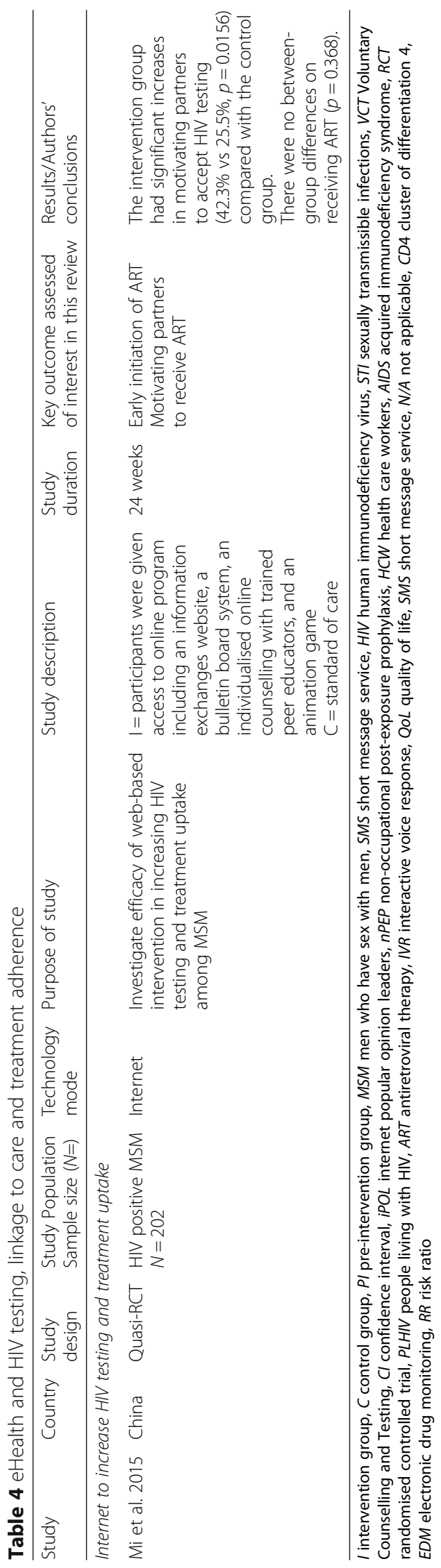


Table 5 Quality assessment

\begin{tabular}{|c|c|c|c|c|c|c|c|c|}
\hline \multirow[t]{2}{*}{ STUDY } & \multirow{2}{*}{$\begin{array}{l}\text { Assigned } \\
\text { design }\end{array}$} & \multicolumn{6}{|c|}{ COMPONENT RATINGS } & \multirow{2}{*}{$\begin{array}{l}\text { GLOBAL } \\
\text { RATING }\end{array}$} \\
\hline & & Selection bias & Study design & Confounders & Blinding & Data collection method & $\begin{array}{l}\text { Withdrawals } \\
\text { and dropouts }\end{array}$ & \\
\hline \multicolumn{9}{|c|}{ eHealth and HIV testing and linkage to care } \\
\hline Bourne et al & Cross-sectional & Moderate & Moderate & Strong & Moderate & Weak & Weak & Moderate \\
\hline Zou et al & Cross-sectional & Weak & Moderate & Weak & Moderate & Weak & Weak & Weak \\
\hline Cheng et al & Cross-sectional & Weak & Weak & Weak & Moderate & Weak & Weak & Weak \\
\hline Ko et al & Cross-sectional & Moderate & Moderate & Strong & Moderate & Weak & Weak & Moderate \\
\hline Minas et al & Cross-sectional & Weak & Moderate & Weak & Moderate & Weak & Weak & Weak \\
\hline Pedrana et al & Cross-sectional & Moderate & Moderate & Weak & Moderate & Weak & Weak & Weak \\
\hline Wilkinson et al & Cohort & Weak & Weak & Weak & Moderate & Weak & Weak & Weak \\
\hline \multicolumn{9}{|c|}{ eHealth and HIV treatment adherence } \\
\hline Huang et al & $\mathrm{RCT}$ & Moderate & Strong & Strong & Moderate & Strong & Strong & Strong \\
\hline Shet et al & $\mathrm{RCT}$ & Moderate & Strong & Strong & Moderate & Strong & Strong & Strong \\
\hline Swendeman et al & Cohort & Weak & Moderate & Weak & Moderate & Weak & Strong & Weak \\
\hline Tran et al & Cross-sectional & Moderate & Weak & Weak & Moderate & Weak & Weak & Weak \\
\hline Uzma et al & $\mathrm{RCT}$ & Moderate & Strong & Strong & Moderate & Strong & Strong & Strong \\
\hline Sabin et al. 2010 & $\mathrm{RCT}$ & Moderate & Strong & Strong & Weak & Strong & Strong & Moderate \\
\hline Sabin et al. 2015 & $\mathrm{RCT}$ & Moderate & Strong & Strong & Moderate & Strong & Strong & Strong \\
\hline Perera et al & $\mathrm{RCT}$ & Moderate & Strong & Strong & Moderate & Strong & Strong & Strong \\
\hline \multicolumn{9}{|c|}{ eHealth and HIV testing, linkage to care and treatment adherence } \\
\hline Mi et al & $\mathrm{RCT}$ & Moderate & Strong & Strong & Moderate & Weak & Strong & Moderate \\
\hline
\end{tabular}

demonstrated significant increases $(p<0.01)$ in the average number of monthly tests among HIV-negative MSM attending three high caseload MSM clinics during the initial and continued campaign periods. However, a 2016 study [63] that further evaluated this intervention using a cohort of MSM over a longer time period, found insufficient evidence to attribute increases in HIV testing exclusively to the campaign.

eHealth applications to improve HIV treatment adherence This review retrieved nine studies that examined the efficacy of eHealth to improve ART adherence. One cross-sectional and three RCT studies concerned the efficacy of reminders via mobile phone calls, alarms or text messages (SMS). The cross-sectional study [57] reported that the use of automated mobile phone alarms were associated with higher optimal adherence measured by a visual analogue scale (VAS) (Coefficient 0.89, 95\% CI 0.02 to $1.99, p<0.01)$.

One RCT study [17] showed significant benefit of weekly phone call reminders together with patient involvement for cue-dosing, on improving ART adherence and virological outcomes. However two other RCT studies [56, 59] did not report significant findings; Huang et al. [56] found no significant improvement in ART adherence associated with bi-weekly three minute reminder phone calls to participants, and neither did Shet et al. [59] when examining the provision of weekly customised and interactive voice call reminders and pictorial messages. This latter study was distinct from all other retrieved studies concerning eHealth and ART adherence in the sample size $(n=631)$ and the duration of the intervention (2 years) which was significantly larger and longer than any of the other studies.

A cohort study from India investigating the efficacy of Interactive Voice Response (IVR) system timed to ART dosing schedules reported significant improvements in adherence however this study was of short duration (1 month), measuring a small sample and relying on self-report as measurement of adherence [64]. A RCT study from China examining a web-based intervention reported no significant impact on ART treatment uptake among MSM, however the intervention group showed a significant increase in motivating partners to accept HIV testing [66].

This review retrieved three RCT studies that investigated the impact of biofeedback eHealth interventions on ART adherence. Perera et al. [58] investigated a biofeedback intervention where participants received daily real-time graphical representations of estimated ART plasma concentrations via a smart phone app. They found that the intervention group had significantly higher self- 
reported adherence scores (48.9 vs. 47.1, $F(1.23)=5.37, p$ $\left.=0.03, \eta \mathrm{p}^{2}=0.19\right)$ and lower viral load (1.3 vs. $1.7, F(1.23)$ $=5.62, p=0.023, \eta p^{2}=0.20$,) at three-month follow-up when compared with the control group. Sabin et al. [60] found that the use of electronic drug monitoring (EDM) feedback and counselling led to a significant improvement in mean ART adherence at month twelve by $9.7 \%$ (86.8$96.5 \%$, t-test statistic $=-2.84 ; p=0.008)$, in the intervention group. The study also confirmed that monthly EDM-informed counselling translated into improved mean CD4 counts in the intervention compared with the control arm (rose by 90 cells/ $\mu \mathrm{l}$ vs. declined by 9 cells $/ \mu \mathrm{l}$, t-test statistic $=-2.4 ; p=0.02$ ). In a subsequent RCT study by the same research team [65], the original EDM intervention was enhanced to include real time wireless medication adherence communication. In the intervention group, optimal adherence was significantly higher at 6 months intervention $(87.3 \%$ vs. $51.8 \%, p<0.001)$, so too was mean adherence throughout the intervention period (96.2\% vs. $89.1 \%, p=0.003)$. Interestingly, clinical outcomes were not maintained post intervention.

With regard to any potential negative impact of the eHealth intervention, Shet et al. [59] noted that although participants did not report adverse events during the study, six of 286 participants interviewed, expressed concerns about intrusiveness and loss of privacy associated with the intervention.

\section{Discussion}

To our knowledge, this is the first systematic review of the evidence for the application of eHealth to improve linkage to and retention in HIV clinical care in the AsiaPacific region. We acknowledge that similar approaches have been applied to other disease areas such as cardiovascular disease and diabetes $[67,68]$. However, for HIV this systematic review is significant in that it synthesises all the important findings related to eHealth for HIV, across the HIV treatment and care cascade. This review found weak to moderate evidence to support the use of eHealth, via text messages, instant messaging, social media and health promotion websites, to increase rates of HIV testing and re-testing among MSM. Evidence regarding the efficacy of eHealth interventions to improve ART adherence using text messages or mobile phone call reminders was mixed. Two strong quality studies [56, 59] found no significant effect, whereas one strong quality study [17] and two weak quality studies [57, 64] reported significant findings. Innovative moderate to strong quality studies where participants received individualised biofeedback about their estimated ART plasma concentration levels, have shown promising results for ART adherence [58, 60, 65].

As can be seen in Fig. 2, this review revealed that a number of studies have shown the usefulness of eHealth tools to facilitate testing, re-testing and ART adherence, however there were no studies investigating the efficacy of eHealth in retention in care. There is much potential to incorporate eHealth interventions to fill the gaps of the HIV treatment and care cascade to reduce rates of loss to follow-up, thus improve retention in HIV care [69]. Retention in care, starting from a positive HIV test to enrolment in care, initiation of ART and continuation of lifelong ART, is critical to ensure the best possible outcomes for PLHIV, reduce development of ART resistance and reduce the incidence of new infections [70].

The findings of the current review have several important implications for future interventions. In October 2014 the Joint United Nations Programme on HIV/ AIDS (UNAIDS) published 90-90-90, an HIV treatment strategy to end the AIDS epidemic. Specifically, the targets of this strategy are that by 2020: 90\% of all PLHIV will know their HIV status; $90 \%$ of all people diagnosed with HIV will receive sustained ART; and 90\% of all people receiving ART will have viral suppression [71]. In a world where the development and expansion of digital technology are growing exponentially, eHealth interventions can have an important role to play in the movement towards the end of AIDS. Regarding the first target of the UNAIDS 90-90-90 strategy, the findings of this review lend support to the effectiveness of SMS reminders, IM and social media campaigns, at increasing HIV testing among MSM, particularly young MSM who are typically early adopters of new technologies [72]. These types of intervention warrant further attention and application in particular among other priority populations who may be marginalised and thus harder-toreach, such as SW, PWID and TG, especially given that eHealth interventions are evidenced to be feasible and acceptable to these groups [21-33]. Concerning the second and third strategy targets, treatment and viral suppression, there is mixed evidence for the efficacy of SMS and mobile phone call reminders to improve adherence. Promising results regarding the efficacy of individualised real-time biofeedback merit further investigation to determine whether such intervention could be further enhanced and cost-effectively rolled out. Furthermore, there remains a lack of longer term and larger scale clinical outcome studies to investigate whether behavioural changes are maintained over time and post intervention.

In line with the recent 2016 WHO Consolidated guidelines on the use of antiretroviral drugs for treating and preventing HIV infection: Recommendations for a public health approach [73] and the 2015 UNFPA Implementing comprehensive HIV and STI programmes with men who have sex with men [35] publications, we recommend that future HIV strategies, policies and planning documents should include guidelines for incorporating eHealth in prevention, testing and treatment programmes. 


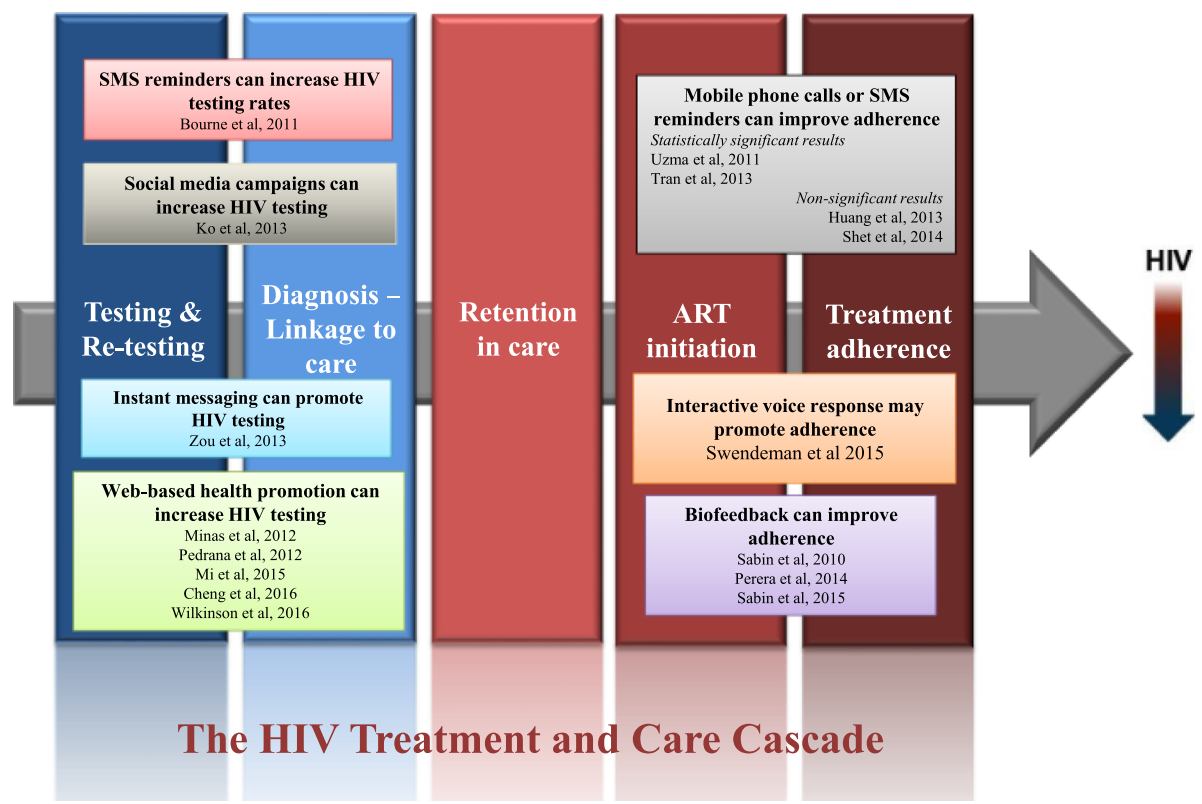

Fig. 2 mHealth interventions across the HIV treatment and care cascade

eHealth can also contribute to the efficacy of preexposure prophylaxsis (PrEP) intervention programmes. There is growing evidence for the role of eHealth interventions in assisting in the rollout of PrEP in priority populations [74]. This information is pertinent to the Asia-Pacific region where countries would benefit from including PrEP in their HIV prevention programmes. HIV testing and re-testing will be very important for increasing uptake of PrEP and also PrEP adherence and prospective evaluations of these interventions should include countries in Asia-Pacific region [75].

In utilising eHealth technologies in HIV programmes and services, it is important that steps are taken to ensure the digital security of any client information collected. Confidentiality and privacy concerns are justifiably heightened among PLHIV given the stigma attached to this diagnosis especially in low and middle income countries where mobile phones may be shared among families and communities. We recommend that future eHealth interventions in HIV take steps to ensure the digital security of confidential information so that PLHIV and people at risk of HIV can confidently engage with these interventions. The WHO GOe list the following parameters that should be included in eHealth security protocols: password protection; network $\log$ in requirements; synchronisation of files to the device; and data backup and recovery [5]. The UNFPA 2015 guideline Implementing comprehensive HIV and STI programmes with men who have sex with men recommends consulting technical experts in ICT security where possible to develop effective security protocols [35]. In line with the Greater Involvement of People Living with HIV (GIPA) principle, consultation with PLHIV in the development of eHealth security protocols should also be prioritised [76].

Although there is emerging evidence to support the use of eHealth in improving HIV outcomes, it is important to consider potential risks associated with the intrusiveness of mobile technologies. In a Kenyan study on SMS reminders to promote ART adherence, Pop-Eleches et al. [77] found that daily text message reminders did not improve ART adherence more than weekly reminders and posited that daily messages were considered intrusive by participants. Similarly, in a meta-analysis of eight RCTs to promote HIV medication adherence, Finitsis et al. [12] noted that increased frequency of daily text messaging showed smaller effects in participants' adherence than interventions that messaged multiple times a week or weekly. Perceptions of intrusiveness will need to be examined further in future eHealth studies, to reduce possible negative impacts of mobile technologies, and maximise optimal outcomes for eHealth interventions.

The findings of this systematic review are inevitably limited by the scope and quality of the original quantitative research. Employing qualitative studies in a systematic review will provide a more in-depth perspectives of the target group of an intervention [78], whether such intervention is feasible, meaningful and appropriate to the target group [79]. An important aspect of evidence synthesis to inform policy and practice is including diverse forms of evidence from different types of research to maximise the findings [80]. No qualitative studies were included in this review, however a mixed method approach should be considered in future systematic reviews. 
This systematic review was broad in its scope enabling the inclusion of a variety of technology interventions to address the HIV testing, care, and treatment among HIV priority populations. Other strengths of this review include a comprehensive and sensitive search strategy that covered all types of eHealth across numerous electronic databases aiming to identify all published and unpublished literature. However, this systematic review has certain limitations. First, although six of the retrieved studies were conducted in China, the restriction of this systematic review to English language articles may have excluded nonEnglish language literature from other Asia-Pacific countries which may have omitted some relevant articles. All of the selected studies were from Asian countries, Australia or New Zealand, with none from Pacific Island countries or territories. Due to the variability of the study characteristics, study designs, type of eHealth interventions and outcome measures, it was not feasible to perform a meta-analysis. All eight of the studies concerning eHealth applications to HIV testing and linkage to care, were rated either weak or moderate in methodological quality, limiting the strength of any findings reported. And finally, all but one of the retrieved studies that investigated treatment and adherence described participants primarily as PLHIV, without further delineation according to priority population groups. This makes drawing conclusions about the efficacy of eHealth in HIV treatment and adherence specifically for priority populations, limited.

\section{Conclusions}

In summary, our review demonstrates encouraging evidence about how eHealth can be used across the HIV treatment and care cascade, including increasing HIV testing in priority populations and ART adherence in the Asia-Pacific region. Moreover the application of eHealth to increasing the uptake of PrEP in priority populations, should also be investigated. These findings can inform HIV programme planning and service delivery regarding the incorporation of eHealth to enhance HIV prevention, testing, treatment, and care. Such interventions are relatively cost-effective, and acceptable to harder to engage priority populations at higher risk of HIV and of dropping out of the HIV treatment and care cascade. The use of eHealth is particularly applicable in the AsiaPacific region where the internet and mobile phone uptake is high.

\section{Endnotes}

${ }^{1}$ The exchange of text messages through a software application in real-time

\section{Additional file}

Additional file 1: Demonstration search strategy for PubMed. (DOC 35 kb)

\begin{abstract}
Abbreviations
AIDS: acquired immunodeficiency syndrome; Apps: mobile phone applications; ART: antiretroviral treatment; BHIVA: British HIV/AIDS Association; CD4: cluster of differentiation 4; CINAHL: Cumulative Index to Nursing and Allied Health Literature; EDM: electronic drug monitoring; GIPA: Greater Involvement of People Living with HIV; GOe: Global Observatory for eHealth; HIV: Human immunodeficiency virus; ICT: information and communication technologies; IM: instant messaging; iPOL: internet popular opinion leaders; IVR: interactive voice response; MeSH: medical subject heading; MSM: men who have sex with man; nPEP: non-occupational post-exposure prophylaxis; PDA: personal digital assistant; PICO: Population, Intervention, Comparison and Outcomes; PLHIV: people living with HIV; PrEP: pre-exposure prophylaxis; PRISMA: Preferred Reporting Items for Systematic Reviews; PWID: people who inject drugs; RCT: randomised controlled trial; SMS: short message service; STI: sexually transmissible infections; SW: sex workers; TG: transgender; UNAIDS: Joint United Nations Programme on HIV/AIDS; UNFPA: United Nations Population Fund; VAS: visual analogue scale; WHO: World Health Organization; WHOLIS: World Health Organization Library Information System
\end{abstract}

\section{Acknowledgements}

The systematic review was proposed by Ying-Ru Lo and Naoko Ishikawa as part of the work plan of The Albion Centre as a WHO Collaborating Centre.

\section{Funding}

No additional funding was used in undertaking this review.

Availability of data and materials

Not applicable

\section{Authors' contributions}

$J P, K C, L M, L Z, J G$ and LF contributed to the conceptualisation and design of the review. LF carried out the systematic literature search in online databases and grey literature. LM, JG and LZ provided technical support and guidance on the study. JP and KC reviewed the articles retrieved for eligibility, conducted data extraction, and analysis, with additional verification by LM and LZ. JP and KC wrote the first draft of the manuscript with input all the authors who then also made intellectual contributions to, read, and approved the final manuscript. RA contributed to the updated literature search, screening of the articles retrieved, data extraction and analysis, and manuscript revision.

Ethics approval and consent to participate

Not applicable

\section{Consent for publication}

Not applicable

\section{Competing interests}

The authors declare that they have no competing interests.

\section{Publisher's Note}

Springer Nature remains neutral with regard to jurisdictional claims in published maps and institutional affiliations.

\section{Author details}

${ }^{1}$ The Albion Centre, South Eastern Sydney Local Health District, 150-154 Albion Street, Sydney, NSW 2010, Australia. ${ }^{2}$ Centre for Social Research in Health, UNSW, Sydney, NSW 2052, Australia. ${ }^{3}$ Centre for Neuroscience and Trauma, Blizard Institute, Queen Mary University of London, London, UK. ${ }^{4}$ Research Center for Public Health, Tsinghua University, Beijing 100084, China. ${ }^{5}$ Melbourne Sexual Health Centre, Alfred Health, Melbourne, Australia. ${ }^{6}$ Central Clinical School, Faculty of Medicine, Monash University, Melbourne, Australia. ${ }^{7}$ School of Public Health and Preventive Medicine, Faculty of Medicine, Monash University, Melbourne, Australia. 
Received: 31 March 2017 Accepted: 19 January 2018

\section{Published online: 17 February 2018}

\section{References}

1. Thompson MA, Mugavero MJ, Amico KR, Cargill VA, Chang LW, Gross R, et al. Guidelines for improving entry into and retention in care and antiretroviral adherence for persons with HIV: evidence-based recommendations from an International Association of Physicians in AIDS care panel. Ann Intern Med. 2012;156(11):817-33.

2. World Health Organization. Metrics for monitoring the cascade of HIV testing, care and treatment services in Asia and the Pacific 2014. Available from: http:// www.searo.who.int/entity/hiv/hiv_metrics.pdf. Accessed 17 Feb 2016.

3. World Health Organization. Global update on HIV treatment 2013: results, impact and opportunities: World Health Organization; 2013. Available from: http://apps.who.int/iris/bitstream/10665/85327/1/WHO_HIV_2013.9_eng.pdf. Accessed 17 Feb 2016.

4. World Health Organization. Atlas eHealth country profiles: based on the findings of the second global survey on eHealth: World Health Organization; 2011. Available from: http://www.who.int/goe/publications/ goe_atlas_2010.pdf. Accessed 17 Feb 2016.

5. World Health Organization. mHealth: New horizons for health through mobile technologies: second global survey on eHealth: World Health Organization; 2011. Available from: http://www.who.int/goe/publications/ goe_mhealth_web.pdf. Accessed 17 Feb 2017.

6. Project PRCGA. Smartphone Ownership and Internet Usage Continues to Climb in Emerging Economies. Available from: http://www.pewglobal.org/ 2016/02/22/smartphone-ownership-and-internet-usage-continues-to-climbin-emerging-economies/. Accessed 20 June 2017.

7. Intelligence G. The Mobile Economy Asia Pacific 2016. Available from: https://www.gsmaintelligence.com/research/?file=

5369cb14451e0db728bd266c7657a251\&download. Accessed 20 June 2017

8. Piette JD, Lun K, Moura LA Jr, Fraser HS, Mechael PN, Powell J, et al. Impacts of e-health on the outcomes of care in low-and middle-income countries: where do we go from here? Bull World Health Organ. 2012;90(5):365-72.

9. Moorhead SA, Hazlett DE, Harrison L, Carroll JK, Irwin A, Hoving C. A new dimension of health care: systematic review of the uses, benefits, and limitations of social media for health communication. J Med Internet Res. 2013;15(4):e85

10. Wantland DJ, Portillo CJ, Holzemer WL, Slaughter R, McGhee EM. The effectiveness of web-based vs. non-web-based interventions: a metaanalysis of behavioral change outcomes. J Med Internet Res. 2004;6(4):e40.

11. Free C, Phillips G, Watson L, Galli L, Felix L, Edwards P, et al. The effectiveness of mobile-health technologies to improve health care service delivery processes: a systematic review and meta-analysis. PLoS Med. 2013; 10(1):e1001363.

12. Finitsis DJ, Pellowski JA, Johnson BT. Text message intervention designs to promote adherence to antiretroviral therapy (ART): a meta-analysis of randomized controlled trials. PLoS One. 2014;9(2):e88166.

13. Horvath T, Azman H, Kennedy GE, Rutherford GW. Mobile phone text messaging for promoting adherence to antiretroviral therapy in patients with HIV infection. Cochrane Database Syst Rev. 2012;3:CD009756.

14. Coomes CM, Lewis MA, Uhrig JD, Furberg RD, Harris JL, Bann CM. Beyond reminders: a conceptual framework for using short message service to promote prevention and improve healthcare quality and clinical outcomes for people living with HIV. AIDS Care. 2012;24(3):348-57.

15. Tran BX, Houston S. Mobile phone-based antiretroviral adherence support in Vietnam: feasibility, patient's preference, and willingness-to-pay. AIDS and Behav. 2012;16(7):1988-92.

16. Wang $H$, Zhou J, Huang L, Li X, Fennie KP, Williams AB. Effects of nursedelivered home visits combined with telephone calls on medication adherence and quality of life in HIV-infected heroin users in Hunan of China. J Clin Nurs. 2010;19(3-4):380-8.

17. Uzma Q, Emmanuel F, Ather U, Zaman S. Efficacy of interventions for improving antiretroviral therapy adherence in HIV/AIDS cases at PIMS, Islamabad. J Int Assoc Phys AIDS Care. 2011;10(6):373-83.

18. Rodrigues R, Bogg L, Shet A, Kumar DS, De Costa A. Mobile phones to support adherence to antiretroviral therapy: what would it cost the Indian National AIDS Control Programme? J Int AIDS Soc. 2014;17:19036.

19. Page TF, Horvath KJ, Danilenko GP, Williams M. A cost analysis of an internet based medication adherence intervention for people living with HIV. J Acquir Immune Defic Syndr. 2012;60(1):1.
20. World Health Organization. Consolidated guidelines on HIV prevention, diagnosis, treatment and care for key populations. Geneva: World Health Organization; 2014.

21. Holt M, Rawstorne P, Wilkinson J, Worth H, Bittman M, Kippax S. HIV testing, gay community involvement and internet use: social and behavioural correlates of HIV testing among Australian men who have sex with men. AIDS Behav. 2012;16(1):13-22.

22. Martin L, Knight V, Read PJ, McNulty A. Clients' preferred methods of obtaining sexually transmissable infection or HIV results from Sydney Sexual Health Centre. Sex Health. 2013;10(1):91-2.

23. Huang L, Nehl E, Lin L, Meng G, Liu Q, Ross M, et al. Sociodemographic and sexual behavior characteristics of an online MSM sample in Guangdong, China. AIDS Care. 2014;26(5):648-52.

24. Lee S, Tam DK, Mak DW, Wong K. Use of the internet for sex partnership in men who have sex with men before HIV infection. Public Health. 2011; 125(7):433-5.

25. Liu S, Wang K, Yao S, Guo X, Liu Y, Wang B. Knowledge and risk behaviors related to HIV/AIDS, and their association with information resource among men who have sex with men in Heilongjiang province, China. BMC Public Health. 2010;10:250.

26. Justumus P, Colby D, Mai Doan Anh T, Balestre E, Becquet R, Orne-Gliemann J. Willingness to use the internet to seek information on HIV prevention and care among men who have sex with men in Ho Chi Minh City, Vietnam. PLoS One. 2013;8(8):e71471.

27. Welles S, Ross M, Banik S, Fisher L, McFarlane M, Kachur R, et al. Demographic and sexual behavior comparisons of Indian and US internet samples of men who have sex with men. Int J Sex Health. 2011;23(2):90-101.

28. Hong $Y$, Li X, Fang X, Lin X, Zhang C. Internet use among female sex workers in China: implications for HIV/STI prevention. AIDS Behav. 2011;15(2):273-82.

29. Xiao Y, Ji G, Tian C, Li H, Biao W, Hu Z. Acceptability and factors associated with willingness to receive short messages for improving antiretroviral therapy adherence in China. AIDS Care. 2014;26(8):952-8.

30. Sidney K, Antony J, Rodrigues R, Arumugam K, Krishnamurthy S, D'Souza G, et al. Supporting patient adherence to antiretrovirals using mobile phone reminders: patient responses from South India. AIDS Care. 2012;24(5):612-7.

31. Anand T, Nitpolprasert C, Kerr SJ, Apornpong T, Ananworanich J, Phanuphak $P$, et al. Implementation of an online HIV prevention and treatment cascade in Thai men who have sex with men and transgender women using Adam's love electronic health record system. J Virus Erad. 2017;3:15-23.

32. Anand T, Nitpolprasert C, Kerr SJ, Muessig KE, Promthong S, Chomchey N, et al. A qualitative study of Thai HIV-positive young men who have sex with men and transgender women demonstrates the need for eHealth interventions to optimize the HIV care continuum. AIDS Care. 2017;7:1-6.

33. Anand T, Nitpolprasert C, Trachunthong D, Kerr SJ, Janyam S, Linjongrat D, et al. A novel online-to-offline (O2O) model for pre-exposure prophylaxis and HIV testing scale up. J Int AIDS Soc. 2017;20:1-11.

34. Bien CH, Best JM, Muessig KE, Wei C, Han L, Tucker JD. Gay apps for seeking sex Partners in China: implications for MSM sexual health. AIDS Behav. 2015: 19(6):941-6.

35. United Nations Population Fund GFoMH, United Nations Development Programme, World Health Organization, United States Agency for International Development, World Bank. Implementing comprehensive HIV and STI programmes with men who have sex with men: practical guidance for collaborative interventions: United Nations Population Fund; 2015. Available from: http://www.unfpa.org/sites/default/files/pub-pdf/MSMIT_for_ Web.pdf. Accessed 17 Feb 2016.

36. Déglise C, Suggs LS, Odermatt P. SMS for disease control in developing countries: a systematic review of mobile health applications. J Telemed Telecare. 2012;18(5):273-81.

37. Van-Velthoven MH, Brusamento S, Majeed A, Car J. Scope and effectiveness of mobile phone messaging for HIV/AIDS care: a systematic review. Psychol Health Med. 2013;18(2):182-202.

38. Gentry S, Van-Velthoven MH, Tudor Car L, Car J. Telephone delivered interventions for reducing morbidity and mortality in people with HIV infection. Cochrane Database Syst Rev. 2013;5:CD009189.

39. Van-Velthoven MH, Tudor Car L, Gentry S, Car J. Telephone delivered interventions for preventing HIV infection in HIV-negative persons. Cochrane Database Syst Rev. 2013:50:CD009190.

40. Claborn KR, Fernandez A, Wray T, Ramsey S. Computer-based HIV adherence promotion interventions: a systematic review. Transl Behav Med. 2015;5(3):294-306. 
41. Mbuagbaw L, Mursleen S, Lytvyn L, Smieja M, Dolovich L, Thabane L. Mobile phone text messaging interventions for HIV and other chronic diseases: an overview of systematic reviews and framework for evidence transfer. BMC Health Serv Res. 2015;15(1):33.

42. Horvath $T$, Azman $H$. Internet-based targeted interventions for preventing HIV infection in men who have sex with men (MSM). In: Cochrane Review Group on HIV/AIDS University of California SF, editor. 2010.

43. Muessig KE, Pike EC, LeGrand S, Hightow-Weidman LB. Mobile phone applications for the care and prevention of HIV and other sexually transmitted diseases: a review. J Med Internet Res. 2013;15(1):e1.

44. Taggart T, Grewe ME, Conserve DF, Gliwa C, Isler MR. Social media and HIV: a systematic review of uses of social media in HIV communication. J Med Internet Res. 2015;17(11):e248.

45. Wei C, Herrick A, Raymond HF, Anglemyer A, Gerbase A, Noar SM. Social marketing interventions to increase HIV/STI testing uptake among men who have sex with men and male-to-female transgender women. Cochrane Database Syst Rev. 2011;9:CD009337.

46. Schnall R, Travers J, Rojas M, Carballo-Diéguez A. eHealth interventions for HIV prevention in high-risk men who have sex with men: a systematic review. J Med Internet Res. 2014;16(5):e134.

47. Catalani $C$, Philbrick W, Fraser $H$, Mechael $P$, Israelski DM. mHealth for HIV treatment \& prevention: a systematic review of the literature. Open AIDS J. 2013;7:17-41.

48. Moher D, Liberati A, Tetzlaff J, Altman DG, Group P. Preferred reporting items for systematic reviews and meta-analyses: the PRISMA statement. PLoS Med. 2009;6(7):e10000097.

49. Thomas H. Quality assessment tool for quantitative studies: McMaster University, Toronto. Available from: http://www.ephpp.ca/tools.html. Accessed 31 Jan 2017.

50. Thomas BH, Ciliska D, Dobbins M, Micucci S. A process for systematically reviewing the literature: providing the research evidence for public health nursing interventions. Worldviews Evid-Based Nurs. 2004;1(3):176-84.

51. Bourne C, Knight V, Guy R, Wand H, Lu H, McNulty A. Short message service reminder intervention doubles sexually transmitted infection/HIV re-testing rates among men who have sex with men. Sex Transm Infect. 2011;87(3):229-31.

52. Ko NY, Hsieh CH, Wang MC, Lee C, Chen CL, Chung AC, et al. Effects of internet popular opinion leaders (iPOL) among internet-using men who have sex with men. J Med Internet Res. 2013;15(2):e40.

53. Zou H, Wu Z, Yu J, Li M, Ablimit M, Li F, et al. Internet-facilitated, voluntary counseling and testing (VCT) clinic-based HIV testing among men who have sex with men in China. PLoS One. 2013:8(2):e51919.

54. Minas B, Laing S, Jordan H, Mak DB. Improved awareness and appropriate use of non-occupational post-exposure prophylaxis (nPEP) for HIV prevention following a multi-modal communication strategy. BMC Public Health. 2012;12:906.

55. Pedrana A, Hellard M, Guy R, El-Hayek C, Gouillou M, Asselin J, et al. Stop the drama Downunder: a social marketing campaign increases HIV/sexually transmitted infection knowledge and testing in Australian gay men. Sex Transm Dis. 2012;39(8):651-8.

56. Huang D, Sangthong R, McNeil E, Chongsuvivatwong V, Zheng W, Yang X. Effects of a phone call intervention to promote adherence to antiretroviral therapy and quality of life of HIV/AIDS patients in Baoshan, China: a randomized controlled trial. AIDS Res Treat. 2013;2013:580974.

57. Tran BX, Nguyen LT, Nguyen NH, Van Hoang Q, Hwang J. Determinants of antiretroviral treatment adherence among HIV/AIDS patients: a multisite study. Glob Health Action. 2013;6:19570.

58. Perera Al, Thomas MG, Moore JO, Faasse K, Petrie KJ. Effect of a smartphone application incorporating personalized health-related imagery on adherence to antiretroviral therapy: a randomized clinical trial. AIDS Patient Care STDs. 2014:28(11):579-86.

59. Shet A, De Costa A, Kumarasamy N, Rodrigues R, Rewari BB, Ashorn P, et al. Effect of mobile telephone reminders on treatment outcome in HIV: evidence from a randomised controlled trial in India. BMJ. 2014;349:95978.

60. Sabin LL, De Silva MB, Hamer DH, Xu K, Zhang J, Li T, et al. Using electronic drug monitor feedback to improve adherence to antiretroviral therapy among HIV-positive patients in China. AIDS Behav. 2010;14(3):580-9.

61. Rodrigues R, Shet A, Antony J, Sidney K, Arumugam K, Krishnamurthy S, et al. Supporting adherence to antiretroviral therapy with mobile phone reminders: results from a cohort in South India. PLoS One. 2012;7(8):e40723.

62. Cheng W, Cai Y, Tang W, Zhong F, Meng G, Gu J, et al. Providing HIVrelated services in China for men who have sex with men. Bull World Health Organ. 2016;94(3):222-7.
63. Wilkinson AL, Pedrana AE, El-Hayek C, Vella AM, Asselin J, Batrouney C, et al. The impact of a social marketing campaign on HIV and sexually transmissible infection testing among men who have sex with men in Australia. Sex Transm Dis. 2016;43(1):49-5.

64. Swendeman D, Jana S, Ray P, Mindry D, Das M, Bhakta B. Development and pilot testing of daily interactive voice response (IVR) calls to support antiretroviral adherence in India: a mixed-methods pilot study. AIDS Behav. 2015;19(Suppl 2):142-55.

65. Sabin LL, Bachman De Silva M, Gill CJ, Zhong L, Vian T, Xie W, et al. Improving adherence to antiretroviral therapy with triggered real-time text message reminders: the China adherence through technology study. J Acquir Immune Defic Syndr. 2015;69:551-9.

66. Mi G, Wu Z, Wang X, Shi CX, Yu F, Li T, et al. Effects of a quasi-randomized web-based intervention on risk behaviors and treatment seeking among HIV-positive men who have sex with men in Chengdu, China. Curr HIV Res. 2015;13(6):490-6.

67. Duff OM, Walsh DM, Furlong BA, O'Connor NE, Moran KA, Woods CB. Behavior change techniques in physical activity eHealth interventions for people with cardiovascular disease: systematic review. J Med Internet Res. 2017;19(8):e281.

68. Norman GJ, Zabinski MF, Adams MA, Rosenberg DE, Yaroch AL, Atienza AA. A review of eHealth interventions for physical activity and dietary behavior change. Am J Prev Med. 2007;33(4):336-45.

69. FHI 360. HIV Cascade Framework for Key Population. 2015. Available from: http://www.fhi360.org/sites/default/files/media/documents/linkages-hivcascade-framework-oct15.pdf. Accessed 26 Sept 2016.

70. World Health Organization. Retention in HIV programmes: defining the challenges and identifying solutions: meeting report, 13-15 September 2011. 2012. Available from: http://apps.who.int/iris/bitstream/10665/44878/ 1/9789241503686_eng.pdf. Accessed 27 Sept 2017.

71. The Joint United Nations Programme on HIV/AIDS. 90-90-90 An ambitious treatment target to help end the AIDS epidemic: UNAIDS; 2014. Available from: http://www.unaids.org/sites/default/files/media_asset/90-90-90_en_0. pdf. Acessed 20 Sept 2016.

72. Ramallo J, Kidder T, Albritton T, Blick G, Pachankis J, Grandelski V, et al. Exploring social networking technologies as tools for HIV prevention for men who have sex with men. AIDS Educ Prev. 2015;27:298-311.

73. World Health Organization. Consolidated guidelines on the use of antiretroviral drugs for treating and preventing HIV infection: recommendations for a public health approach. Second ed. Geneva: World Health Organization; 2016.

74. Anand T, Nitpolprasert C, Ananworanich J, Pakam C, Nonenoy S, Jantarapakde $J$, et al. Innovative strategies using communications technologies to engage gay men and other men who have sex with men into early HIV testing and treatment in Thailand. J Virus Erad. 2015;1(2):111-5.

75. Zablotska I, Grulich AE, Phanuphak N, Anand T, Janyam S, Poonkasetwattana $M$, et al. PrEP implementation in the Asia-Pacific region: opportunities, implementation and barriers. J Int AIDS Soc. 2016;19(7(Suppl 6)):21119.

76. The Joint United Nations Programme on HIV/AIDS. Policy Brief: The Greater Involvement of People Living with HIV (GIPA). UNAIDS; 2007. Available from: http://data.unaids.org/pub/BriefingNote/2007/jc1299_policy_brief_gipa.pdf. Accessed 20 Sept 2016.

77. Pop-Eleches C, Thirumurthy H, Habyarimana JP, Zivin JG, Goldstein MP, de Walque $\mathrm{D}$, et al. Mobile phone technologies improve adherence to antiretroviral treatment in a resource-limited setting: a randomized controlled trial of text message reminders. AIDS. 2011;25(6):825-34.

78. Thomas J, Harden A, Oakley A, Oliver S, Sutcliffe K, Rees R, et al. Integrating qualitative research with trials in systematic reviews. BMJ. 2004;328(7446):1010-2.

79. Pearson A, Wiechula R, Court A, Lockwood C. The JBI model of evidencebased healthcare. Int J Evid Based Healthc. 2005;3(8):207-15.

80. Pearson A, White H, Bath-Hextall F, Salmond S, Apostolo J, Kirkpatrick P. A mixed-methods approach to systematic reviews. Int J Evid Based Healthc. 2015;13(3):121-31. 